\title{
Erratum to: Synthesis and anti-HIV-1 screening of novel $N^{\prime}$-(1-(aryl)ethylidene)-2-(5,5-dioxido-3- phenylbenzo $[e]$ pyrazolo $[4,3-c][1,2]$ thiazin- $4(1 H)-$ yl)acetohydrazides
}

\author{
Sana Aslam • Matloob Ahmad • Muhammad Zia-ur-Rehman • \\ Catherine Montero • Mervi Detorio • \\ Masood Parvez • Raymond F. Schinazi
}

Published online: 10 August 2013

(c) The Pharmaceutical Society of Korea 2013

Erratum to: Arch. Pharm. Res.

DOI 10.1007/s12272-013-0200-9

We apologise for an error in one of the references in this paper.

In the Introduction there is a reference to work from Maria et al. (2013). This is incorrect. The reference is to work by Barreca et al. (2013).

The first sentence of the 4th paragraph of the Introduction should read as follows:

Keeping in view the pharmacological importance of these two pharmacophores, i.e., pyrazole and

The online version of the original article can be found under doi:10.1007/s12272-013-0200-9.

\section{S. Aslam}

Institute of Chemistry, University of the Punjab, Lahore 54590,

Pakistan

M. Ahmad ( $\square)$

Department of Chemistry, Government College University,

Faisalabad 38000, Pakistan

e-mail: matloob_123@yahoo.com

M. Zia-ur-Rehman

Applied Chemistry Research Centre, PCSIR Laboratories

Complex, Lahore 54600, Pakistan

C. Montero - M. Detorio - R. F. Schinazi

Department of Pediatrics, Center for AIDS Research, Emory

University School of Medicine, Decatur, GA 30033, USA

C. Montero $\cdot$ M. Detorio $~$ R. F. Schinazi

The Veterans Affairs Medical Center, Decatur, GA 30033, USA

M. Parvez

Department of Chemistry, The University of Calgary,

2500 University Drive NW, Calgary, AB T2N 1N4, Canada 1,2-benzothiazine (Fig. 1), we have incorporated both heterocyclic nuclei into one therapeutic unit as pyrazolobenzothiazine. Some derivatives of this ring system are recently reported as inhibitors of $\mathrm{HCV}$ replication (Barreca et al. 2013).

The correct reference is as follows:

Barreca ML, Manfroni G, Leyssen P, Winquist J, KaushikBasu N, Paeshuyse J, Krishnan R, Iraci N, Sabatini S, Tabarrini O, Basu A, Danielson UH, Neyts J, Cecchetti V (2013) Structure-based discovery of pyrazolobenzothiazine derivatives as inhibitors of hepatitis $\mathrm{C}$ virus replication. J Med Chem 56:2270-2282

We apologise for any inconvenience/confusion caused. 